\title{
Glycemic status and risks of thromboembolism and major bleeding in patients with atrial fibrillation
}

Yi-Hsin Chan ${ }^{1,2,3 \dagger}{ }^{+}$Chi Chuang $^{1 \dagger}$, Cze-Ci Chan ${ }^{1}$, Hsin-Fu Lee ${ }^{1,2,4}$, Ya-Chi Huang ${ }^{5}$, Yu-Tung Huang ${ }^{5}$, Shang-Hung Chang ${ }^{1,2,5}$, Chun-Li Wang ${ }^{1,2}$, Tze-Fan Chao ${ }^{6,7^{*}}$, Chi-Tai Kuo ${ }^{1,2}$, Yung-Hsin Yeh ${ }^{1,2}$ and Shih-Ann Chen ${ }^{6,7}$

\begin{abstract}
Background: Studies specifically examining the association between glycated hemoglobin A1c (HbA1c) levels and ischemic stroke/systemic thromboembolism (IS/SE) risk in atrial fibrillation (AF) patients are limited. Here, we investigated the association between $\mathrm{HbA} 1 \mathrm{c}$ levels and the risk of IS/SE, as well as major bleeding, among AF patients with or without oral anticoagulants (OACs). We also compared the effectiveness and safety of warfarin and direct oral anticoagulants (DOACs) in different HbA1c categories.

Methods: We utilized medical data from a multi-center healthcare provider in Taiwan, which included 34,036 AF patients with serum $\mathrm{HbA1c}$ data available within 3 months after AF being diagnosed. Patients were divided into seven study groups according to their HbA1c levels: $<5.4 \%, 5.4 \%-5.6 \%, 5.7 \%-5.9 \%, 6.0 \%-6.4 \%, 6.5 \%-6.9 \%, 7.0 \%-7.9 \%$, and $\geq 8.0 \%$. The risks of IS/SE and major bleeding were compared among the groups after adjusting for baseline stroke and bleeding risk factors.

Results: Compared with the patients with $\mathrm{HbA} 1 \mathrm{c}$ level $<5.4 \%$, IS/SE risk significantly increased at HbA1c levels higher than 6.5\% [adjusted hazard ratio (HR): 1.20, 95\% confidence interval (Cl): 1.00-1.43 for HbA1c level 6.5\%-6.9\%; 1.32, (95\% Cl 1.11-1.57) for HbA1c level 7.0\%-7.9\%; and 1.48 (95\% Cl 1.25-1.76) for $\mathrm{HbA} 1 \mathrm{c}$ level $\geq 8.0 \%$ ]. These results were generally consistent in AF patients without OACs $(n=24,931)$. However, among 9105 patients receiving OACs, IS/ $\mathrm{SE}$ risk was not higher for patients having higher $\mathrm{HbA} 1 \mathrm{c}$ levels. The risk of major bleeding was comparable across all HbA1c categories. Compared with warfarin, DOACs were associated with lower risks of IS/SE (adjusted HR: 0.61, 95\% $\mathrm{Cl} 0.49-0.75$ ) and major bleeding (adjusted HR: $0.30,95 \% \mathrm{Cl} 0.21-0.42$ ) without interactions across different HbA1C categories (all $P$ interactions $>0.05$ ).

Conclusion: For AF patients, IS/SE risk significantly increased once HbA1c levels exceeded 6.5\%, and OACs may attenuate these associations. Compared with warfarin, DOACs were more effective and safer across broad HbA1c categories. Therefore, in addition to prescribing DOACs when indicated, more aggressive glycemic control to achieve an $\mathrm{HbA1c}$ level $<6.5 \%$ may be considered for eligible AF patients and should be tested in further prospective studies.
\end{abstract}

Keywords: Atrial fibrillation, HbA1c, Ischemic stroke, Major bleeding, Direct oral anticoagulants, Warfarin

*Correspondence: eyckeyck@gmail.com

${ }^{\dagger}$ Yi-Hsin Chan and Chi Chuang contributed equally to the study and manuscript

${ }^{6}$ Division of Cardiology, Department of Medicine, Taipei Veterans General Hospital, No. 201, Sec. 2, Shih-Pai Road, Taipei, Taiwan

Full list of author information is available at the end of the article

\section{Background}

Diabetes mellitus (DM), insulin resistance, and obesity are among the major risk factors for atrial fibrillation (AF) $[1,2]$. DM is also a crucial risk factor in many widely used stroke prediction schemes (e.g., $\mathrm{CHADS}_{2}$ and

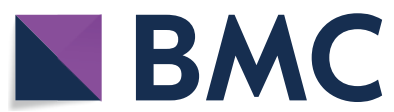

(c) The Author(s) 2020. This article is licensed under a Creative Commons Attribution 4.0 International License, which permits use, sharing, adaptation, distribution and reproduction in any medium or format, as long as you give appropriate credit to the original author(s) and the source, provide a link to the Creative Commons licence, and indicate if changes were made. The images or other third party material in this article are included in the article's Creative Commons licence, unless indicated otherwise in a credit line to the material. If material is not included in the article's Creative Commons licence and your intended use is not permitted by statutory regulation or exceeds the permitted use, you will need to obtain permission directly from the copyright holder. To view a copy of this licence, visit http://creativeco mmons.org/licenses/by/4.0/. The Creative Commons Public Domain Dedication waiver (http://creativecommons.org/publicdomain/ zero/1.0/) applies to the data made available in this article, unless otherwise stated in a credit line to the data. 
$\mathrm{CHA}_{2} \mathrm{DS}_{2}$-VASc scores) for patients with AF $[3,4]$. Glycated hemoglobin A1c (HbA1c) is an indicator of longterm glycemic control, and elevated HbA1c is a reliable marker reflecting chronic hyperglycemia [5, 6]. Previous studies indicated a significant dose-response association between HbA1c levels and the risk of stroke in DM patients without AF [7-9]. However, studies that specifically examine the association between HbA1c levels and the risk of thromboembolism in AF patients have been limited and showed conflicting data [10-12]. Therefore, it remains unclear whether poor glycemic control, represented by high HbA1c, is significantly associated with an increased risk of ischemic stroke/systemic thromboembolism (IS/SE) among AF patients. In addition, although DM itself is not currently considered as an independent risk factor of bleeding in the bleeding scheme [13], recent studies indicated that it could be independently associated with an increased risk of major bleeding in AF patients $[14,15]$.

In this study, we investigated the association between HbA1c levels and the risks of IS/SE as well as major bleeding in around 34,000 AF patients with or without oral anticoagulants (OACs) using a large multicenterbased electronic medical registry database. Besides, we also compared the effectiveness and safety of warfarin and direct oral anticoagulants (DOACs) among $\mathrm{AF}$ patients in different HbA1c categories.

\section{Methods}

This study was approved by the Institutional Review Board of the Chang Gung Medical Foundation and based on the data from Chang Gung Research Database provided by Chang Gung Memorial Hospital. The interpretation and conclusions presented here do not represent the position of Chang Gung Memorial Hospital.

\section{Database}

All patients' data until 2019 were collected from the Chang Gung Memorial Hospital (CGMH) Medical System, which is the largest healthcare provider in Taiwan. The CGMH Medical System consists of four tertiary care medical centers and three major teaching hospitals, with total hospital beds of up to 10,000 and around 280,000 patients being admitted per year [16]. In 2015, there were approximately 500,000 emergency department visits and $8,600,000$ outpatient department visits to the CGMH, accounting for $10 \%$ of the Taiwanese medical service annually $[16,17]$. The advantage of the CGMH medical database is that each patient's detailed chart record, diagnosis, imaging, and laboratory data are all available [18]. The identification number and personal information of each patient were encrypted and de-identified by using a consistent encrypting procedure; therefore, informed consent was waived for this study.

\section{Study population}

We retrospectively studied 70,408 patients over 20 years old in whom new-onset AF was diagnosed between January 1, 2001, and May 31, 2018, from the CGMH medical database. There were 34,036 patients with serum HbA1c data within 3 months after the diagnosis of AF. The index date was defined as the date of baseline HbA1c in the CGMH Patient Register during the inclusion period. First, we categorized our study population into no-DM (HbA1c $<5.7 \%$; $n=8059)$, pre-DM $(5.7 \%-6.4 \%$; $\mathrm{n}=13,852)$, and $\mathrm{DM}(\geq 6.5 \% ; \mathrm{n}=12,125)$ subgroups according to the ADA guidelines [19]. Subsequently, we further divided our patients into two $[<5.4 \%(\mathrm{n}=2994)$ and $5.5 \%-5.6 \%(\mathrm{n}=5065)]$, two $[5.7 \%-5.9 \%(\mathrm{n}=6526)$ and $6.0 \%-6.4 \%(7336)]$, and three $[6.5 \%-6.9 \%(\mathrm{n}=3908)$, $7.0 \%-7.9 \%(\mathrm{n}=3903)$, and $\geq 8.0 \%(\mathrm{n}=4314)]$ subgroups among the no-DM, pre-DM, and DM subgroups. The cut-off values used within the pre-DM $(<5.4 \%$ and $5.5 \%-$ $5.6 \%)$ and $\mathrm{DM}(6.5 \%-6.9 \%, 7.0 \%-7.9 \%$, and $\geq 8.0 \%)$ subgroups were chosen to result in similar patient numbers between these subgroups. We set $\mathrm{HbA} 1 \mathrm{c}<5.4 \%$ as the reference group in the present study because an HbA1c level of $5.4 \%$ corresponds to fasting plasma glucose of $100 \mathrm{mg} / \mathrm{dl}$ [19]. Patients were finally divided into seven study groups according to their baseline $\mathrm{HbA1c}$ levels: HbA1c of $<5.4 \%(n=2994), 5.4 \%-5.6 \%(n=5065)$, 5.7\%-5.9\% ( $\mathrm{n}=6516), 6.0 \%-6.4 \%(\mathrm{n}=7336), 6.5 \%-6.9 \%$ $(n=3908), 7.0 \%-7.9 \%(n=3903)$, and $\geq 8.0 \%(n=4314)$. A flow chart of the study is presented in Fig. 1.

\section{Follow-up and outcome}

The clinical outcomes of the present study were the first occurrences of hospitalized IS/SE and major bleeding. The diagnosis of IS/SE should be confirmed by a corresponding chart record plus medical imaging including brain computed tomography/ magnetic resonance imaging. The major bleeding events were defined as hospitalization due to symptomatic bleeding in a critical organ including brain, gastrointestinal tract, or other critical sites, bleeding causing a decrease in hemoglobin level of $\geq 2 \mathrm{~g} / \mathrm{dL}$, bleeding leading to blood transfusion of $\geq 2$ units, or fatal bleeding. All study outcomes were defined based on first discharge diagnosis to avoid misclassifications. Patients were followed up from the date of first recorded HbA1c until the first occurrence of any study outcome, mortality, or end date of the study (May 31, 2018). 


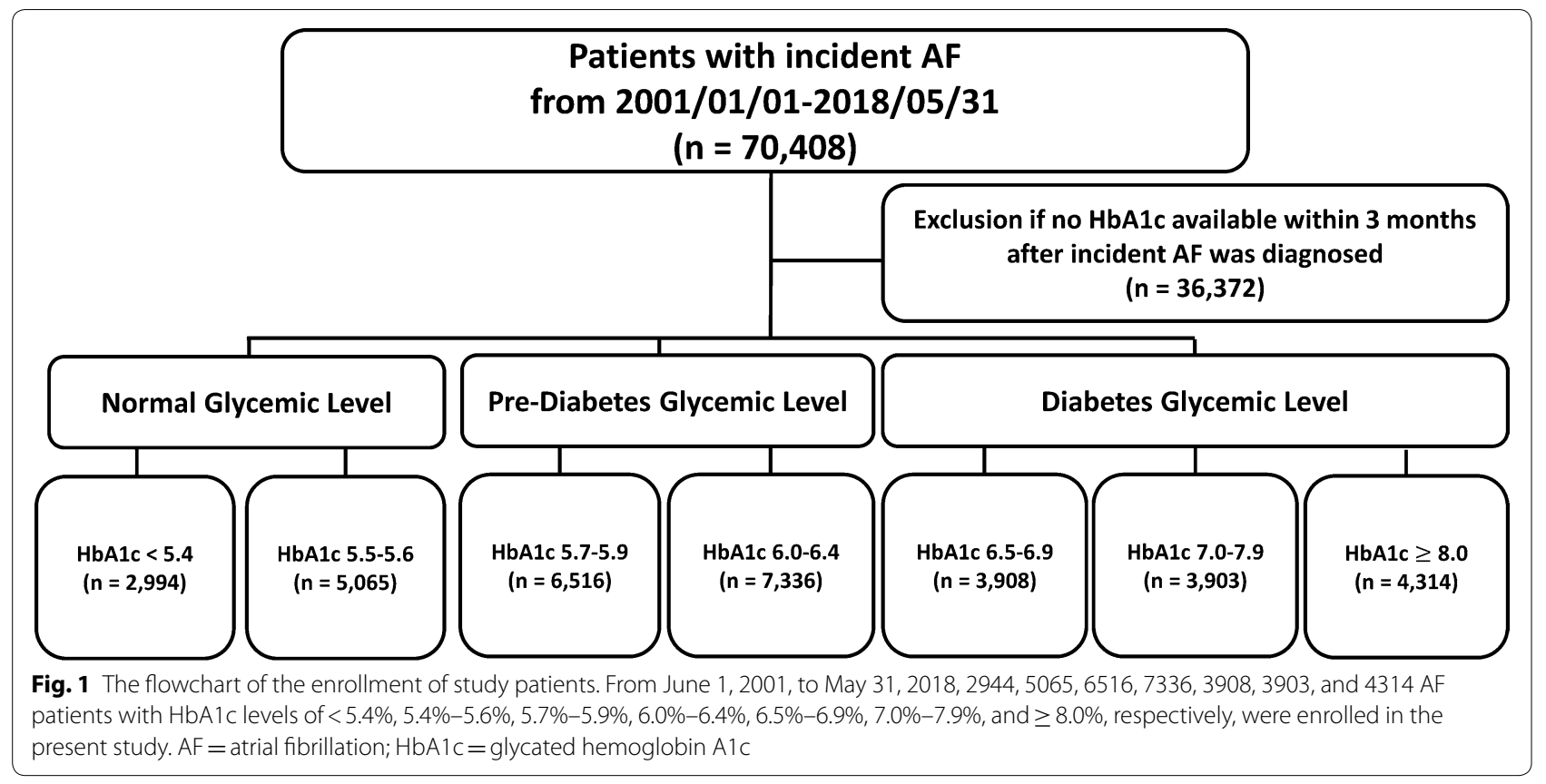

\section{Covariates}

Baseline covariates were obtained from any claim records with the diagnoses, procedures, or medication codes before the index date. Baseline prescription medicine was confined to medications taken at least once within 3 months before the index date. Bleeding history was confined to events within 6 months preceding the index date. The $\mathrm{CHA}_{2} \mathrm{DS}_{2}$-VASc score (congestive heart failure, hypertension, age 75 years or older for 2 points, DM, previous stroke or transient ischemic attack for 2 points, vascular disease, age 65 to 74 years, and female gender) was used to predict the risk of IS/SE in AF patients $[20,21]$. The HAS-BLED score [hypertension, abnormal renal or liver function, stroke, bleeding history, labile international normal ratio (INR), age 65 years or older, and antiplatelet drug or alcohol use] was used to predict the risk of bleeding in AF patients treated with OACs [13].

\section{Statistical analysis}

Data are presented as mean and standard deviation for continuous variables and as proportions for categorical variables. ANOVA was used to analyze the differences for continuous variables. $X^{2}$ test was used to analyze the differences for nominal variables. Crude incidence rates were computed as the total number of study outcomes during the follow-up time divided by person-years at risk. Multivariate Cox proportional hazards regression was used to compare the risk of events in AF patients across different HbA1c categories. Statistical significance was defined as a $P$ value of $<0.05$. All analyses were conducted using SAS 9.2 (SAS Institute Inc., Cary, NC, USA).

\section{Results}

\section{Baseline characteristics}

The clinical characteristics of AF patients in different HbA1c categories are shown in Table 1. In general, patients with a higher baseline $\mathrm{HbA1c}$ level had a higher $\mathrm{CHA}_{2} \mathrm{DS}_{2}$-VASc score, a higher prevalence of dyslipidemia, heavier body weight, and a lower estimated glomerular filtration rate (eGFR). In groups with higher HbA1c levels, a higher percentage received insulin or oral hypoglycemic agents (OHAs), angiotensin-convertingenzyme inhibitors (ACEIs)/angiotensin II receptor antagonists $(\mathrm{ARBs})$, and statins $(P<0.0001)$. Approximately $60 \%$ of patients had baseline echocardiography data in each HbA1c group. In general, patients with a higher baseline HbA1c level had a lower left ventricular ejection fraction value $(P<0.0001)$.

\section{Associations between $\mathrm{HbA1c}$ and risks of IS/SE and major bleeding}

In general, the crude incidence rate of IS/SE of $\mathrm{AF}$ patients continuously increased across $\mathrm{HbA1c}$ categories, but the crude incidence rates of major bleeding were similar in different HbA1c groups (Table 2). The cumulative incidence curves of IS/SE and major bleeding of different HbA1c groups are shown in Fig. 2. The risk of IS/ $\mathrm{SE}$ appeared to be higher in patients with a higher HbA1c level $(6.5 \%-6.9 \%, 7.0 \%-7.9 \%$, and $\geq 8.0 \%$ ) (log-rank 
Table 1 Baseline characteristics of AF patients in different $\mathrm{HbA1c}$ categories

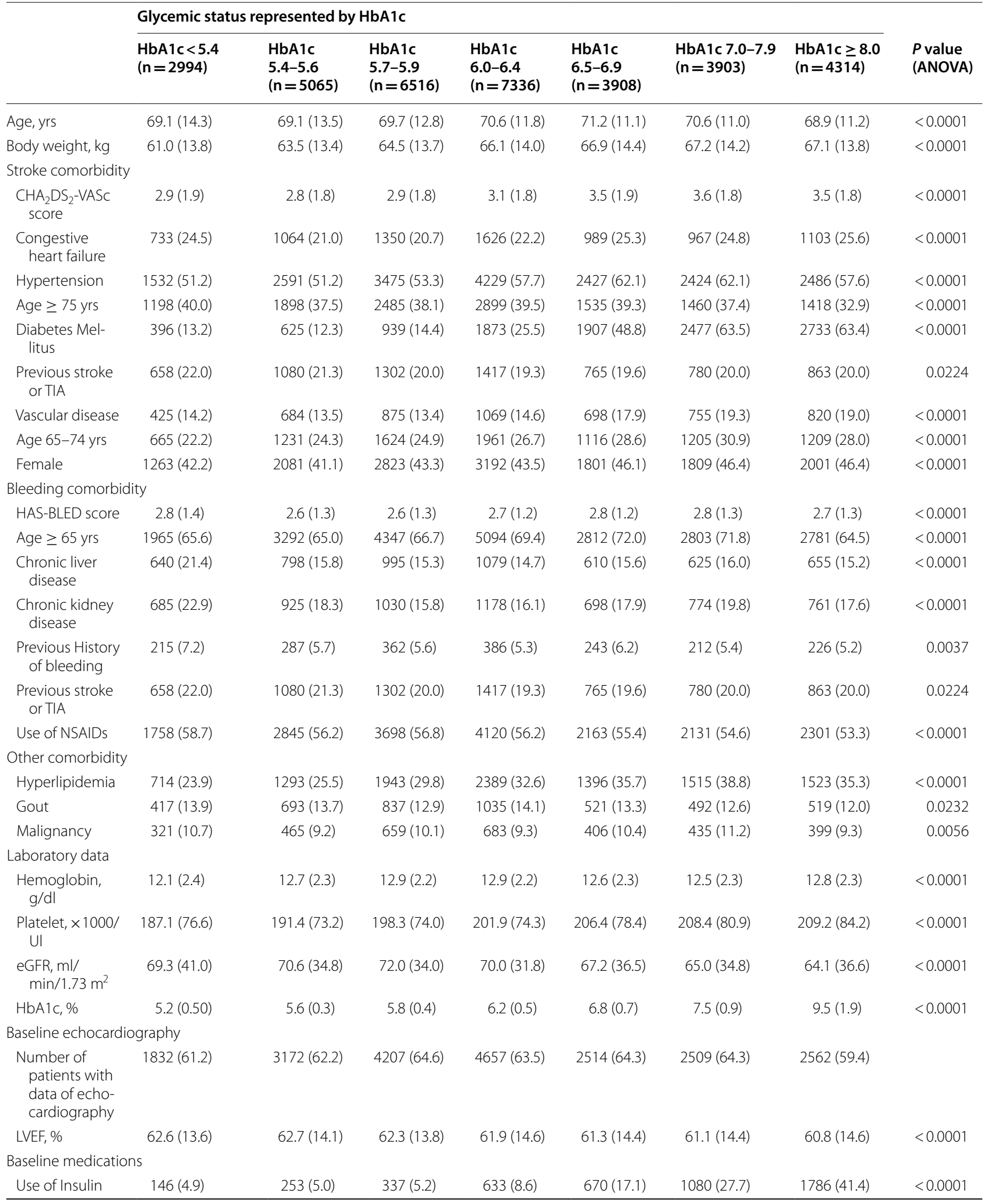


Table 1 (continued)

\begin{tabular}{|c|c|c|c|c|c|c|c|c|}
\hline & \multicolumn{7}{|c|}{ Glycemic status represented by $\mathrm{HbA} 1 \mathrm{c}$} & \multirow[b]{2}{*}{$\begin{array}{l}P \text { value } \\
\text { (ANOVA) }\end{array}$} \\
\hline & $\begin{array}{l}\mathrm{HbA} 1 \mathrm{c}<5.4 \\
(\mathrm{n}=2994)\end{array}$ & $\begin{array}{l}\text { HbA1c } \\
5.4-5.6 \\
(n=5065)\end{array}$ & $\begin{array}{l}\mathrm{HbA} 1 \mathrm{c} \\
5.7-5.9 \\
(n=6516)\end{array}$ & $\begin{array}{l}\text { HbA1c } \\
6.0-6.4 \\
(n=7336)\end{array}$ & $\begin{array}{l}\mathrm{HbA1c} \\
6.5-6.9 \\
(n=3908)\end{array}$ & $\begin{array}{l}\text { HbA1c } 7.0-7.9 \\
(n=3903)\end{array}$ & $\begin{array}{l}\operatorname{HbA} 1 c \geq 8.0 \\
(n=4314)\end{array}$ & \\
\hline $\begin{array}{l}\text { Use of OHAs, } \\
\text { not including } \\
\text { SGLT2i and } \\
\text { GLP1 agonist }\end{array}$ & $208(6.9)$ & $308(6.1)$ & $554(8.5)$ & $1321(18.0)$ & $1442(36.9)$ & $1930(49.4)$ & $2103(48.7)$ & $<0.0001$ \\
\hline Use of SGLT2i & $15(0.5)$ & $45(0.9)$ & $68(1.0)$ & $187(2.6)$ & $212(5.4)$ & $365(9.4)$ & $526(12.2)$ & $<0.0001$ \\
\hline $\begin{array}{l}\text { Use of GLP1 } \\
\text { agonist }\end{array}$ & $0(0)$ & $0(0)$ & $0(0)$ & $0(0)$ & $1(0.0)$ & $1(0.0)$ & $3(0.1)$ & 0.0028 \\
\hline Use of warfarin & $459(15.3)$ & $796(15.7)$ & $1051(16.1)$ & $1082(14.8)$ & $579(14.8)$ & $563(14.4)$ & $609(14.1)$ & 0.0498 \\
\hline Use of DOACs & $264(8.8)$ & $541(10.7)$ & $824(12.7)$ & $1030(14.0)$ & $513(13.1)$ & $438(11.2)$ & $356(8.3)$ & $<0.0001$ \\
\hline Use of NSAIDs & $410(13.7)$ & $588(11.6)$ & $739(11.3)$ & $947(12.9)$ & $508(13.0)$ & $494(12.7)$ & $601(13.9)$ & $<0.0001$ \\
\hline Use of ACEI/ARB & $1209(40.4)$ & 2167 (42.8) & 2855 (43.8) & $3559(48.5)$ & 1966 (50.3) & 2006 (51.4) & $2048(47.5)$ & $<0.0001$ \\
\hline $\begin{array}{l}\text { Use of loop } \\
\text { diuretics }\end{array}$ & $842(28.1)$ & $1257(24.8)$ & $1591(24.4)$ & $1993(27.2)$ & $1262(32.3)$ & $1265(32.4)$ & $1493(34.6)$ & $<0.0001$ \\
\hline $\begin{array}{l}\text { Use of amiodar- } \\
\text { one }\end{array}$ & $577(19.3)$ & $983(19.4)$ & 1105 (17.0) & $1279(17.4)$ & 728 (18.6) & $678(17.4)$ & $661(15.3)$ & $<0.0001$ \\
\hline $\begin{array}{l}\text { Use of dronedar- } \\
\text { one }\end{array}$ & $47(1.6)$ & $76(1.5)$ & $103(1.6)$ & $89(1.2)$ & $43(1.1)$ & $42(1.1)$ & $18(0.4)$ & $<0.0001$ \\
\hline $\begin{array}{l}\text { Use of beta- } \\
\text { blocker }\end{array}$ & $1222(40.8)$ & $2183(43.1)$ & $2947(45.2)$ & $3457(47.1)$ & $2011(51.5)$ & $1950(50.0)$ & $2003(46.4)$ & $<0.0001$ \\
\hline Use of diltiazem & $396(13.2)$ & $721(14.2)$ & 1025 (15.7) & 1145 (15.6) & 699 (17.9) & $721(18.5)$ & $756(17.5)$ & $<0.0001$ \\
\hline Use of verapamil & $127(4.2)$ & $206(4.1)$ & $258(4.0)$ & $313(4.3)$ & $168(4.3)$ & $184(4.7)$ & $174(4.0)$ & 0.6483 \\
\hline Use of digoxin & $498(16.6)$ & 740 (14.6) & 1005 (15.4) & $1204(16.4)$ & $698(17.9)$ & $735(18.8)$ & $1054(24.4)$ & $<0.0001$ \\
\hline Use of statin & $368(12.3)$ & 838 (16.5) & $1330(20.4)$ & $1720(23.5)$ & $1073(27.5)$ & $1144(29.3)$ & $1098(25.5)$ & $<0.0001$ \\
\hline
\end{tabular}

Data are expressed as mean \pm standard deviation or as numbers (percentage)

$A C E l$ angiotensin-converting-enzyme inhibitor, $A F$ atrial fibrillation, $A P T$ antiplatelet agent, $A R B$ angiotensin II receptor antagonists, $C H A_{2} D S_{2}-V A S C$ congestive heart failure, hypertension, age 75 years or older, diabetes mellitus, previous stroke/transient ischemic attack, vascular disease, age 65 to 74 years, female, $D O A C s$ direct oral anticoagulants, eGFR estimated glomerular filtration rate, GLP1 glucagon -like peptide-1, HAS-BLED hypertension, abnormal renal or liver function, stroke, bleeding history, labile INR, age 65 years or older, and antiplatelet drug or alcohol use, HbA1c glycated hemoglobin A1c, LVEF left ventricular ejection fraction, OHAs oral hypoglycemic agent, NSAIDs non-steroidal anti-inflammatory drugs, SGLT2i sodium glucose co-transporter-2 inhibitor, TIA transient ischemic attack

$P<0.0001)$, while the risk of major bleeding did not differ significantly across all groups (log-rank $P=0.0926)$.

Compared with patients with an HbA1c level of $<5.4 \%$, the risk of IS/SE significantly increased when the HbA1c level was higher than 6.5\% [adjusted hazard ratio (aHR) 1.20, 95\% confidence interval (CI) 1.00$1.43, P=0.0450$ for $\mathrm{HbA} 1 \mathrm{c}$ level of $6.5 \%-6.9 \% ; 1.32$, 95\% CI 1.11-1.57, $P=0.0019$ for HbA1c level of $7.0 \%-$ 7.9\%; and 1.48, 95\% CI 1.25-1.76, $P<0.0001$ for HbA1c level of $\geq 8.0 \%$ ] after adjustments for $\mathrm{CHA}_{2} \mathrm{DS}_{2}$-VASc score, use of OACs, use of insulin/OHAs, and eGFR (Table 2 and Fig. 3). The risk of IS/SE was similar for patients with an HbA1c level of 5.4\%-5.6\%, $5.7 \%-5.9 \%$, and $6.0 \%-6.4 \%$ compared with those with $\mathrm{HbA} 1 \mathrm{c}<5.4 \%$. In contrast to the risk of IS/SE, the risk of major bleeding was comparable across all HbA1c categories (Table 2 and Fig. 3).

We also performed a sensitivity analysis in which all patients were categorized into three groups according to the ADA definitions by HbA1c levels, that is,
non-DM (HbA1c $<5.7 \%)$, pre-DM (HbA1c 5.7\%-6.4\%), and DM groups $(\mathrm{HbA1c} \geq 6.5 \%)$. The results are consistent with the main analysis, which indicated that the DM group [aHR: 1.26 (95\% CI 1.13-1.41), $P<0.0001$ ], but not the pre-DM group [aHR: 1.02, (95\% CI $0.92-$ 1.14), $P=0.6560$ ], was associated with a significantly higher risk of IS/SE when compared with the non-DM group. In contrast, the risk of major bleeding did not differ significantly across these three groups (Table 3).

\section{Associations between $\mathrm{HbA} 1 \mathrm{c}$ and risks of IS/SE and major bleeding in AF patients known to have DM or with unknown DM status}

We also performed analyses for AF patients known to have DM or with unknown DM status in each HbA1c category. Patients were defined as having "known DM" if DM had already been diagnosed before the HbA1c data were available $(n=14,097)$. The definition of "unknown" DM included patients without DM $($ HbA1c $<6.5 \%)$ and those with DM newly diagnosed 
Table 2 Risks of hospitalized IS/SE and major bleeding among AF patients in different $\mathrm{HbA1C}$ categories

\begin{tabular}{|c|c|c|c|c|c|}
\hline & \multirow{2}{*}{$\begin{array}{l}\text { Event rate/100 person-years } \\
(95 \% \mathrm{Cl})\end{array}$} & \multicolumn{2}{|l|}{ Crude } & \multicolumn{2}{|l|}{ Adjusted } \\
\hline & & $\mathrm{HR}(95 \% \mathrm{CI})$ & $P$ value & $\mathrm{HR}(95 \% \mathrm{Cl})^{a}$ & $P$ value \\
\hline \multicolumn{6}{|l|}{ IS/SE } \\
\hline $\mathrm{HbA} 1 \mathrm{c}<5.4$ & $1.20(1.04-1.36)$ & 1.00 (Reference) & - & 1.00 (Reference) & - \\
\hline HbA1c 5.4-5.6 & $1.33(1.20-1.47)$ & $1.06(0.9-1.26)$ & 0.4926 & $1.08(0.92-1.28)$ & 0.3508 \\
\hline $\mathrm{HbA} 1 \mathrm{c} 5.7-5.9$ & $1.41(1.29-1.54)$ & $1.1(0.93-1.29)$ & 0.2576 & $1.12(0.96-1.32)$ & 0.1571 \\
\hline $\mathrm{HbA} 1 \mathrm{c} 6.0-6.4$ & $1.31(1.20-1.42)$ & $1.02(0.87-1.2)$ & 0.7701 & $1.04(0.88-1.22)$ & 0.6659 \\
\hline HbA1c 6.5-6.9 & $1.47(1.31-1.63)$ & $1.21(1.01-1.43)$ & 0.0341 & $1.2(1-1.43)$ & 0.0450 \\
\hline HbA1c $7.0-7.9$ & $1.55(1.40-1.71)$ & $1.32(1.12-1.56)$ & 0.0011 & $1.32(1.11-1.57)$ & 0.0019 \\
\hline \multirow[t]{3}{*}{$\mathrm{HbA} 1 \mathrm{c} \geq 8.0$} & $1.53(1.39-1.67)$ & $1.39(1.18-1.63)$ & $<0.0001$ & $1.48(1.25-1.76)$ & $<0.0001$ \\
\hline & \multirow{2}{*}{$\begin{array}{l}\text { Event rate/100 person-years } \\
(95 \% \mathrm{CI})\end{array}$} & Crude & Adjusted & \multirow[t]{2}{*}{$\mathrm{HR}(95 \% \mathrm{Cl})^{\mathbf{b}}$} & \multirow[t]{2}{*}{$P$ value } \\
\hline & & HR $(95 \% \mathrm{CI})$ & $P$ value & & \\
\hline \multicolumn{6}{|l|}{ Major bleeding } \\
\hline $\mathrm{HbA1c}<5.4$ & $0.84(0.71-0.97)$ & 1.00 (Reference) & - & 1.00 (Reference) & - \\
\hline HbA1c 5.4-5.6 & $0.76(0.65-0.86)$ & $0.86(0.7-1.06)$ & 0.1554 & $0.9(0.73-1.11)$ & 0.3136 \\
\hline HbA1c 5.7-5.9 & $0.75(0.66-0.84)$ & $0.84(0.69-1.02)$ & 0.0770 & $0.88(0.72-1.08)$ & 0.2178 \\
\hline HbA1c 6.0-6.4 & $0.78(0.69-0.87)$ & $0.88(0.72-1.06)$ & 0.1770 & $0.89(0.73-1.08)$ & 0.2353 \\
\hline $\mathrm{HbA} 1 \mathrm{c} 6.5-6.9$ & $0.85(0.73-0.97)$ & $1(0.81-1.24)$ & 0.9942 & $0.94(0.76-1.17)$ & 0.5790 \\
\hline HbA1c $7.0-7.9$ & $0.83(0.72-0.95)$ & $1.02(0.83-1.26)$ & 0.8314 & $0.93(0.75-1.16)$ & 0.5121 \\
\hline $\mathrm{HbA} 1 \mathrm{c} \geq 8.0$ & $0.78(0.68-0.87)$ & $1.01(0.83-1.24)$ & 0.9151 & $0.92(0.74-1.15)$ & 0.4700 \\
\hline
\end{tabular}

$($ HbA1c $\geq 6.5 \%)(n=19,939)$ after HbA1c data were available. There was no interaction observed for known or unknown DM regarding the risk of IS/SE compared with that in patients with an HbA1c of $<5.4 \%$ in each HbA1c category ( $P$ interaction $>0.05$ in all categories) (Fig. 4). There was also a significant trend for an increased risk of IS/SE among patients having an HbA1c of $6.5 \%-6.9 \%, 7.0 \%-7.9 \%$, and $\geq 8.0 \%$ for patients known to have DM or with an unknown DM status (for trends, both $P<0.0001$ ) (Fig. 4). There was no significant difference in the risk of major bleeding across all HbA1c categories in AF patients known to have DM or with unknown DM status (Fig. 4).

\section{Associations between $\mathrm{HbA} 1 \mathrm{c}$ and risk of IS/SE in AF patients treated with or without OACs}

The results from analyzing the risk of IS/SE were generally consistent with the main analysis when we focused on AF patients not taking OACs $(n=24,931)$ : aHR 1.31 (95\% CI 1.07-1.60) $(P=0.0086)$ for HbA1c level of $6.5 \%-6.9 \% ; 1.32$ (95\% CI 1.08-1.61) $(P=0.0076)$ for HbA1c level of 7.0\%-7.9\%; and 1.54 (95\% CI 1.26-1.87)
$(P<0.0001)$ for HbA1c level $\geq 8.0 \%$ compared with patients with $\mathrm{HbA} 1 \mathrm{c}<5.4 \%$ (Fig. 5). However, for 9105 patients receiving OACs (3966 with DOACs and 5139 with warfarin), the risk of IS/SE was not higher among patients with a higher HbA1c level than in those with HbA1c $<5.4 \%$ (Fig. 5).

\section{DOACs versus warfarin in AF patients with different $\mathrm{HbA1c}$} categories

Among the DOAC users, 727 (18.3\%), 1176 (29.7\%), $389(9.8 \%)$, and $1674(42.2 \%)$ patients were treated with apixaban, dabigatran, edoxaban, and rivaroxaban, respectively. Overall, DOACs were associated with lower risks of IS/SE (aHR 0.61, 95\% CI 0.49-0.75, $P<0.0001$ ) and major bleeding (aHR 0.30, 95\% CI 0.21-0.42, $P<0.0001$ ) without interactions across different HbA1c categories $(P$ interaction $>0.05$ for both endpoints) (Fig. 6).

\section{Discussion}

Main findings

In our study, we investigated the impacts of HbA1c level, in 34,036 AF patients with different glycemic control, on the risks of IS/SE and major bleeding. The main findings 

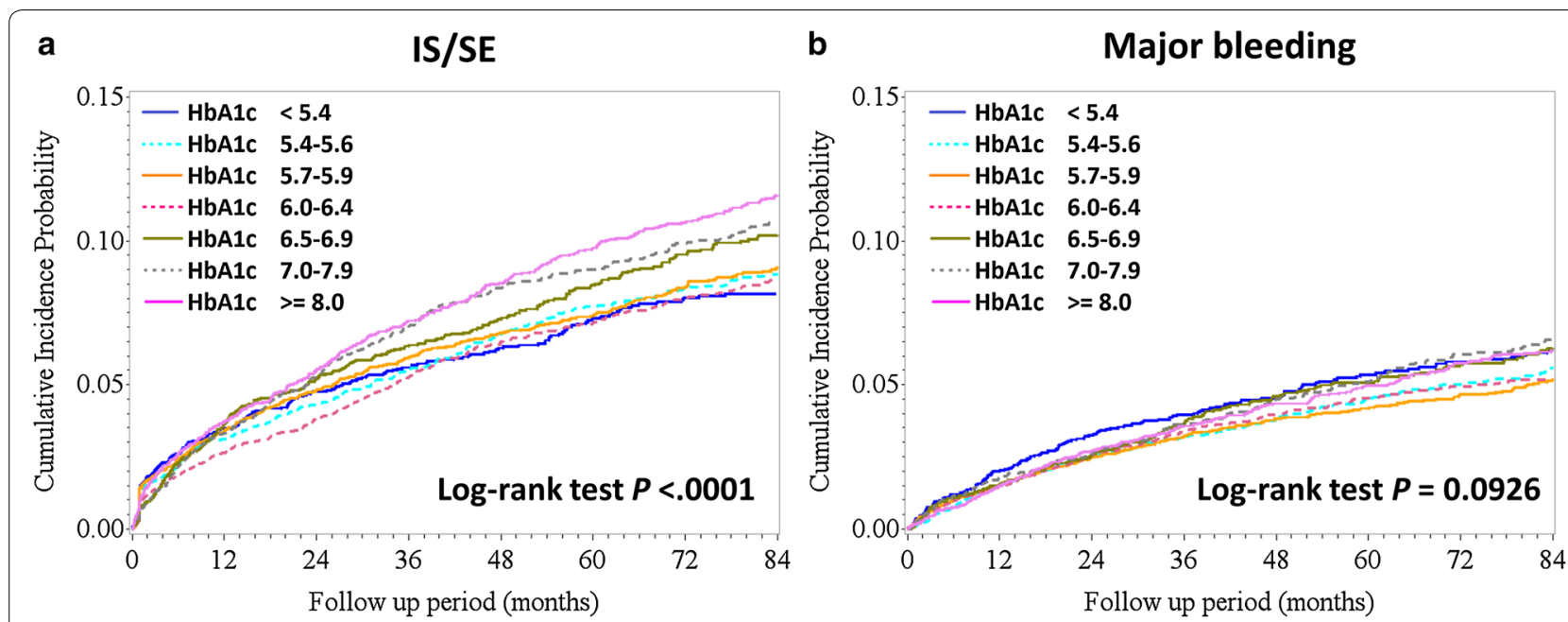

Number at risk

Number at risk

\begin{tabular}{|c|c|c|c|c|c|c|c|c|c|c|c|c|c|c|c|}
\hline-2 & 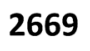 & & & & & & & & & & & & & & \\
\hline 5 & 15 & & 470 & & & & & & 2 & & & & & & \\
\hline-6 & 518 & & & & & & & & & & & & & & \\
\hline .73 & 979 & & & & & & & & & & & & & & \\
\hline 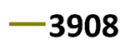 & & & & & & & & 8 & & & & & & & 25 \\
\hline 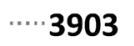 & & & & & & & & 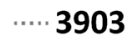 & & & & & & & 0 \\
\hline & & 99 & 126 & 50 & 576 & 336 & 73 & -4314 & 3950 & 3592 & 249 & 962 & 0 & 456 & 18 \\
\hline
\end{tabular}

Fig. 2 Cumulative incidence curves of IS/SE (a) and major bleeding (b) among AF patients in different HbA1c categories. Thromboembolic events appeared to be higher in patients with higher $\mathrm{HbA1}$ c levels of $6.5 \%-6.9 \%, 7.0 \%-7.9 \%$, and $\geq 8.0 \%$ than in the other groups (log-rank $P<0.0001)$, while the risk of major bleeding was comparable across all groups (log-rank $P=0.0926) . A F=$ atrial fibrillation; $\mathrm{HbA1c}=$ glycated hemoglobin $\mathrm{A} 1 \mathrm{c}$; IS/SE = ischemic stroke/systemic embolism

of this study are as follows: (i) The HbA1c level, irrespective of the presence of established DM or use of insulin/ OHAs, is associated with a significantly increased risk of IS/SE once the HbA1c level is $\geq 6.5 \%$ in AF patients. (ii) The risk of major bleeding is comparable across all HbA1c categories. (iii) The associations between HbA1c levels and the risk of IS/SE among AF patients seemed to be attenuated with OAC use. (iv) Compared with warfarin, DOACs are associated with lower risks of IS/SE and major bleeding in each HbA1c category.

\section{Associations between $\mathrm{HbA} 1 \mathrm{c}$ levels and risks of IS/SE and major bleeding}

Several studies investigated the associations between HbA1c levels and risk of systemic thromboembolism in AF patients [10-12]. Saliba et al. found that the HbA1c level was associated with a higher risk of ischemic stroke in a dose-response manner among 11,176 AF patients with type $2 \mathrm{DM}$, which is consistent with our findings [10]. However, the cut-off level of HbA1c at which the risk of thromboembolism significantly increased was $7 \%$, rather than $6.5 \%$ as demonstrated in our study. Fangel et al. studied $5386 \mathrm{AF}$ patients with type $2 \mathrm{DM}$ and showed that a higher risk of thromboembolism was observed among patients with an HbA1c level of $>6.6 \%$ compared with those with an HbA1c level of $\leq 6.5 \%$ [12]. However, this association was only significant among patients with a DM duration of $<10$ years. Ashburner et al. studied $2101 \mathrm{AF}$ patients with DM in the ATRIA California community-based cohort and showed that a DM duration of $>3$ years was a more important predictor of ischemic stroke than HbA1c level itself [11]. In our study, a higher risk of IS/SE was observed for Asian AF patients having an HbA1c level of $>6.5 \%$. However, whether more aggressive glycemic control to achieve an HbA1c level of $<6.5 \%$, rather than $<7.0 \%$ suggested by the American Diabetes Association for the general diabetic population [22], could lower the risk of IS/SE in AF patients deserves further study. Moreover, we also demonstrated that the risk of major bleeding did not differ significantly in different HbA1c categories, and these findings support the commonly used bleeding prediction scheme, HAS-BLED score, which does not include DM as a risk factor component for bleeding [13]. However, the meta-analysis of four pivotal DOAC trials showed that the rates of major bleeding were $6.35 \%$ in patients 


\section{IS/SE}

$1.20 *$

$1.32 *$

1.48*

(1.01-1.43) (1.11-1.57) (1.25-1.76)

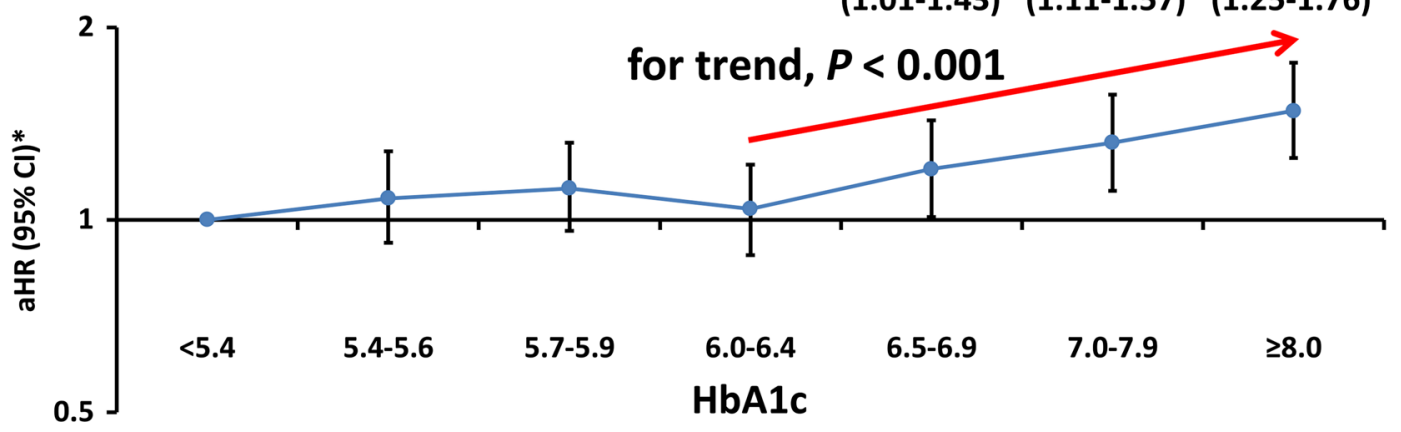

Major bleeding

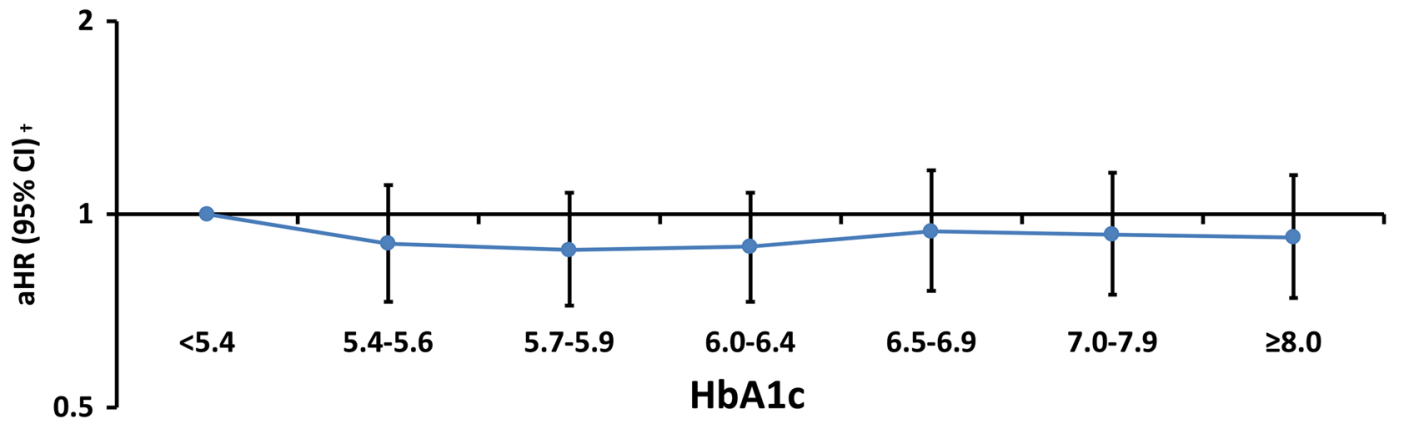

Fig. 3 Risks of IS/SE and major bleeding for AF patients in different HbA1c categories. Compared with patients with an $\mathrm{HbAc1}$ level of $<5.4 \%$, the risk of IS/SE significantly increased when $\mathrm{HbA1c}$ level was higher than $6.5 \%$, while the risk of IS/SE was similar for patients with $\mathrm{HbA} 1 \mathrm{C}$ levels of $5.4 \%-5.6 \%, 5.7 \%-5.9 \%$, and $6.0 \%-6.4 \%$. In contrast to the risk of IS/SE, the risk of major bleeding was comparable across all HbA1c categories. ${ }^{*}$ Risk of IS/SE was adjusted for $\mathrm{CHA}_{2} \mathrm{DS}_{2}$-VASC score, use of insulin or OHAs, use of warfarin or DOACs, and eGFR. †Risk of major bleeding was adjusted for HAS-BLED score, use of insulin or OHAs, use of warfarin or DOACs, and eGFR. AF = atrial fibrillation; $\mathrm{Cl}=$ confidence interval; DOAC $=$ direct oral anticoagulant; $\mathrm{eGFR}=$ estimated glomerular filtration rate; $\mathrm{HbA1C}=$ glycated hemoglobin A1c; aHR=adjusted hazard ratio; IS/SE = ischemic stroke or systemic embolism; $\mathrm{OHA}=$ oral hypoglycemic agent

Table 3 Risks of hospitalized IS/SE and major bleeding among AF patients with non-diabetes, pre-diabetes, and diabetes

\begin{tabular}{|c|c|c|c|c|c|}
\hline & \multirow{2}{*}{$\begin{array}{l}\text { Event rate/100 person- } \\
\text { years }(95 \% \mathrm{CI})\end{array}$} & \multicolumn{2}{|l|}{ Crude } & \multicolumn{2}{|l|}{ Adjusted } \\
\hline & & $\mathrm{HR}(95 \% \mathrm{Cl})$ & $P$ value & $\mathrm{HR}(95 \% \mathrm{Cl})^{\mathrm{a}}$ & $P$ value \\
\hline \multicolumn{6}{|l|}{ IS/SE } \\
\hline Non-diabetes (HbA1c < 5.7\%) & $1.28(1.18-1.38)$ & 1.00 (Reference) & - & 1.00 (Reference) & - \\
\hline Pre-diabetes (HbA1c 5.7-6.4\%) & $1.36(1.27-1.44)$ & $1.02(0.92-1.13)$ & 0.6968 & $1.02(0.92-1.14)$ & 0.6560 \\
\hline \multirow[t]{3}{*}{ Diabetes (HbA1c $\geq 6.5 \%)$} & $1.52(1.43-1.61)$ & $1.26(1.14-1.39)$ & $<0.0001$ & $1.26(1.13-1.41)$ & $<0.0001$ \\
\hline & \multirow{2}{*}{$\begin{array}{l}\text { Event rate/100 person- } \\
\text { years }(95 \% \mathrm{Cl})\end{array}$} & \multicolumn{2}{|l|}{ Crude } & \multicolumn{2}{|l|}{ Adjusted } \\
\hline & & $\mathrm{HR}(95 \% \mathrm{Cl})$ & $P$ value & $\mathrm{HR}(95 \% \mathrm{Cl})^{\mathrm{b}}$ & $P$ value \\
\hline \multicolumn{6}{|l|}{ Major bleeding } \\
\hline Non-diabetes (HbA1c < 5.7\%) & $0.79(0.71-0.87)$ & 1.00 (Reference) & - & 1.00 (Reference) & - \\
\hline Pre-diabetes (HbA1c 5.7-6.4\%) & $0.76(0.70-0.83)$ & $0.94(0.82-1.07)$ & 0.3298 & $0.94(0.83-1.08)$ & 0.3881 \\
\hline Diabetes (HbA1c $\geq 6.5 \%)$ & $0.82(0.75-0.88)$ & $1.11(0.97-1.26)$ & 0.1184 & $0.99(0.86-1.15)$ & 0.9122 \\
\hline
\end{tabular}

adjustments for $\mathrm{CHA}_{2} \mathrm{DS}_{2}$-VASc score, use of insulin or OHAs, use of warfarin or DOACs, and eGFR

${ }^{b}$ Adjustments for HAS-BLED score, use of insulin or OHAs, use of warfarin or DOACs, and eGFR

AF atrial fibrillation, $C l$ confidence interval, DOACs direct oral anticoagulants, eGFR estimated glomerular filtration rate, HbA1c glycated hemoglobin A1c, HR hazard ratio, IS/SE ischemic stroke or systemic embolism, OHAs oral hypoglycemic agents 


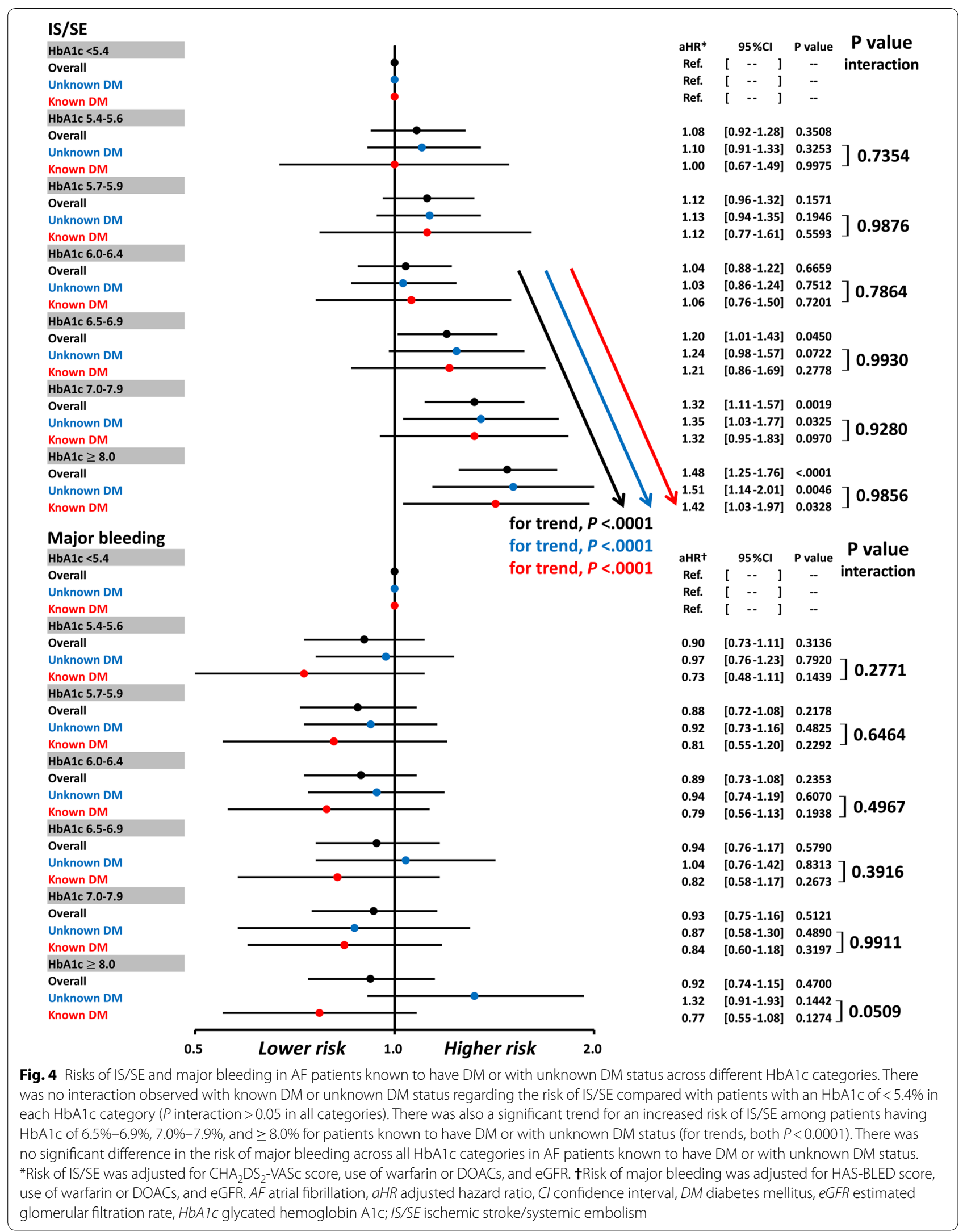



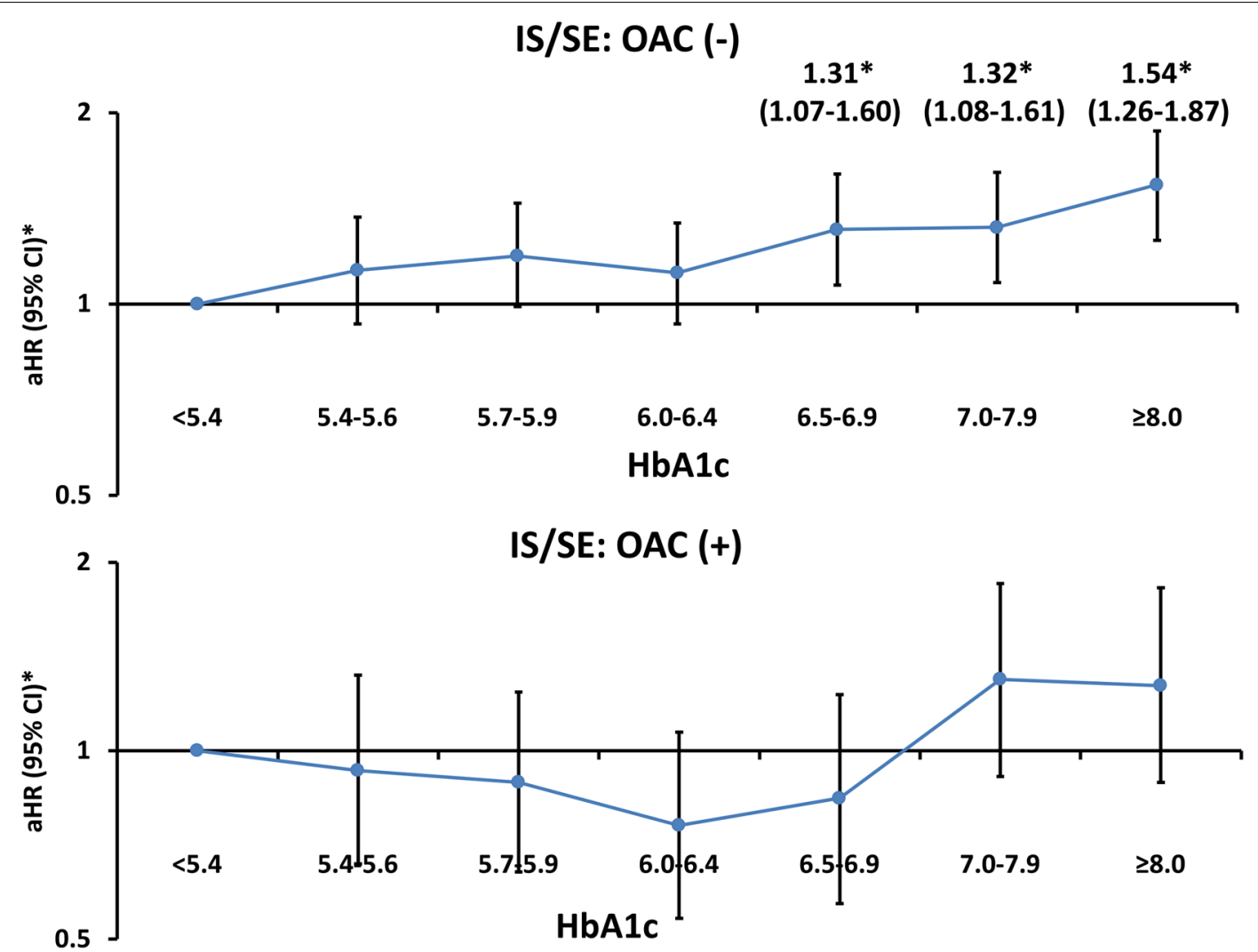

Fig. 5 Risk of IS/SE for AF patients with/without taking OACs across different HbA1c categories. Results about the analysis of risk of IS/SE were generally consistent with the main analysis when we focused on AF patients not taking OACs ( $n=24,931)$. However, for 9105 patients receiving OACs (3966 with DOACs and 5139 with warfarin), the risk of IS/SE was not higher among patients with a higher HbA1c level than in those with $\mathrm{HbA} 1 \mathrm{c}$ of $<5.4 \%$. *Risk of IS/SE was adjusted for $\mathrm{CHA}_{2} \mathrm{DS}_{2}$-VASC score, use of insulin or OHAs, and eGFR. AF atrial fibrillation, aHR adjusted hazard ratio, Cl confidence interval, DOAC direct oral anticoagulant, eGFR estimated glomerular filtration rate, HbA1c glycated hemoglobin A1c, IS/SE ischemic stroke/systemic embolism, OAC oral anticoagulant

with DM vs. $5.40 \%$ in those without DM $(P<0.0001)[23]$. A high prevalence of comorbid hypertension and renal dysfunction due to advanced diabetes, which are indeed included as risk factor components of the HAS-BLED score, may result in a higher risk of bleeding for DM patients. We should pay attention to the overlap of these factors with DM when managing anticoagulated diabetic AF patients.

Furthermore, we found a high rate of prescription of nonsteroidal anti-inflammatory drugs (NSAIDs) in our AF population across different HbA1c categories (Table 1). A previous study also showed that NSAIDs were commonly used among AF patients who initiated OACs [24]. Although most AF patients took NSAIDs transiently rather than regularly in the present study, previous studies already indicated that even transient use of NSAIDs could pose a serious risk of both cardiovascular events and bleeding [25, 26]. Kent et al. studied the effects of NSAIDs in the RE-LY trial, which included 18,113 patients, 2279 of whom had used NSAIDs at least once during the follow-up. The risks of stroke/SE [HR: 1.50 (95\% CI 1.12-2.01), $P=0.007$ ], major bleeding [HR: 1.68 (95\% CI 1.402.02), $P<0.0001$ ], and hospitalization [HR: $1.64(95 \%$ CI 1.51-1.77), $P<0.0001]$ were significantly higher with NSAIDs, irrespective of receiving DOACs or warfarin [27]. Further prospective study is necessary to investigate this issue among the diabetic AF population.

\section{Associations between $\mathrm{HbA} 1 \mathrm{c}$ levels and risk of IS/SE among patients on OACs}

Interestingly, our study also showed that the use of OACs may attenuate the dose-response linear association between HbA1c and the risk of IS/SE in AF patients. Previous randomized studies, ADVANCE and ACCORD trials $[28,29]$, did not show benefits of intensive glycemic control on reducing major macrovascular events; one explanation of this is that the widespread use of statins may play a more important role in stroke 


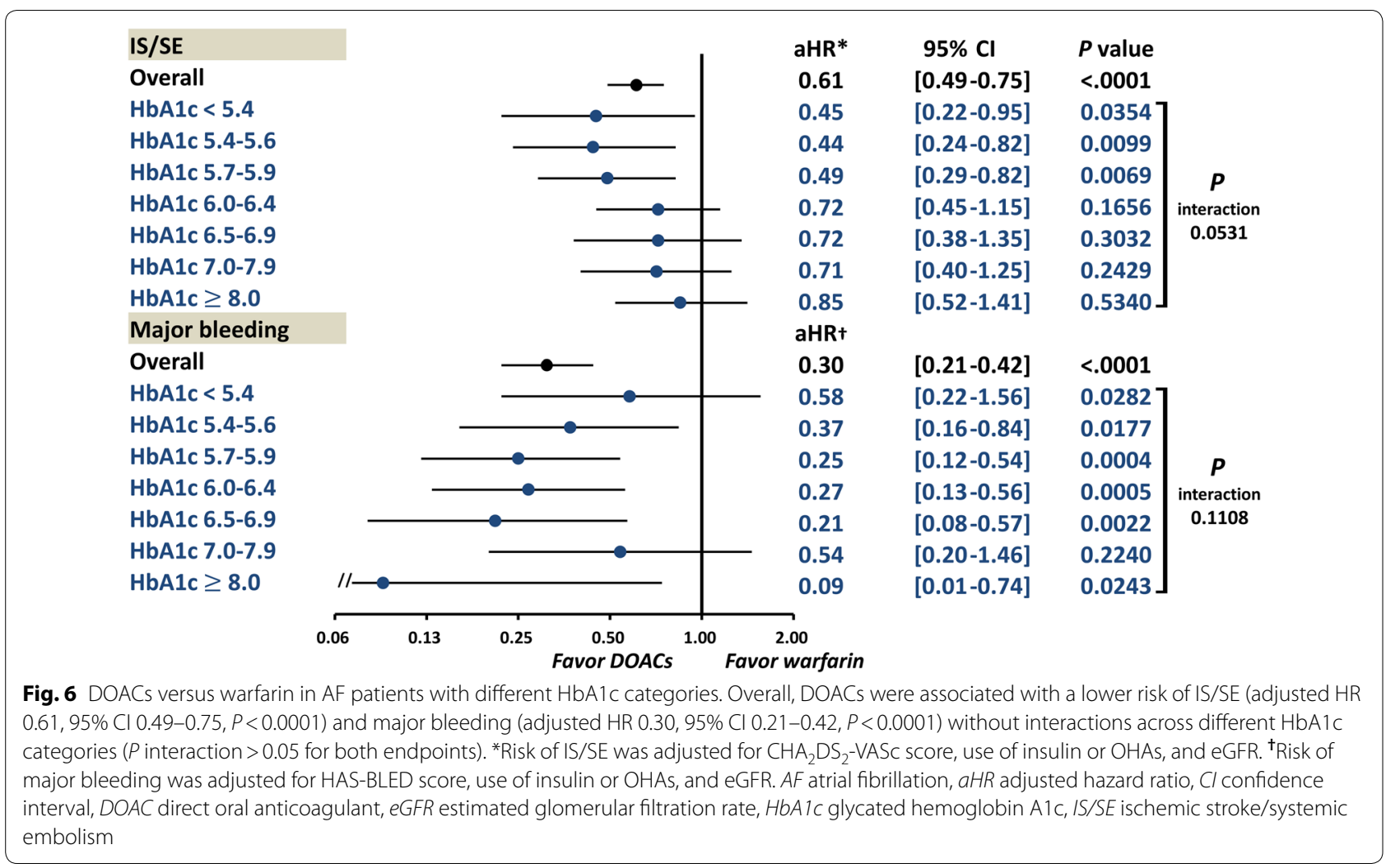

prevention for diabetic patients. Similarly, a possible explanation of our finding is that the most important and effective method to reduce AF-associated stroke is the use of OACs; therefore, the impact of glycemic control on the risk of IS/SE was attenuated. This is partly supported by the post hoc analysis of the ROCKET-AF trial, indicating that the presence of DM was associated with a higher risk of myocardial infarction $(2.60 \%$ vs. $1.57 \%)$, but not a higher risk of IS/SE (2.99\% vs. $3.52 \%)$, among AF patients fully anticoagulated with rivaroxaban or warfarin [30]. However, our findings should not be misinterpreted as showing that glycemic control is not important for anticoagulated AF patients. The key message is that OACs should be prescribed for AF patients whenever indicated, along with efforts toward glycemic control.

\section{Comparisons of DOACs and warfarin in different $\mathrm{HbA1c}$ categories}

We also demonstrated that DOACs were associated with lower risks of IS/SE and major bleeding than warfarin across different HbA1c categories. The RE-LY and ARISTOTLE studies indicated that dabigatran at $110 \mathrm{mg}$ twice daily and apixaban at $5 / 2.5 \mathrm{mg}$ twice daily were associated with significantly lower risks of major bleeding than warfarin [31, 32]. However, the benefits of reduced major bleeding for dabigatran at $110 \mathrm{mg}$ or apixaban at 5/2.5 mg over warfarin were not significant in AF patients with DM in the post hoc analysis of these pivotal trials [15, 33]. Actually, there were no clear data showing the benefits of DOACs over warfarin regarding the risk of major bleeding in AF patients with DM [34, 35]. As we know, warfarin may have several drawbacks, especially in diabetic AF patients. Variability of glycemic level in diabetic patients may affect the pharmacokinetics of warfarin, which may increase the risk of INR values outside the target range in diabetic AF patients [36]. Indeed, the presence of diabetes was independently associated with poor TTR in warfarin-treated AF patients [37]. Furthermore, warfarin inhibits the vitamin K-dependent gamma-glutamyl carboxylation of proteins, including matrix Gla protein and osteocalcin (bone Gla protein); therefore, the use of warfarin may increase the risk of vascular calcification and osteoporotic bone fracture in diabetic AF patients [38]. Our study supported the advantages of DOACs over warfarin regarding efficacy and safety in AF patients across a broad spectrum of HbA1c levels [34, 38, 39]. However, further randomized and prospective studies assessing the safety of DOACs vs. warfarin in patients with concomitant AF and type 2 DM are warranted. 


\section{Study limitations}

There were several limitations in our study. First, this was a retrospective study and 36,372 AF patients whose HbA1c data were lacking were excluded from the analysis. Therefore, some biases may have been present and whether patients whose $\mathrm{HbA1c}$ data were available could represent the whole AF population remained unclear. Furthermore, the clinical characteristics of the patients were different across the different HbA1c categories. Although we adjusted for $\mathrm{CHA}_{2} \mathrm{DS}_{2}$-VASc or HAS-BLED score, use of insulin or OHAs, use of warfarin or DOACs and eGFR in the multivariate Cox regression models, other residual confounding factors were probably present. Second, the CGMH database lacks some patient information, including physical activity, alcohol intake, smoking, and blood pressure. Therefore, it is unclear whether the impacts of HbA1c levels on the risk of IS/SE were partially confounded by these factors. Besides, since data about echocardiography were lacking in around $40 \%$ of patients, we were not able to further characterize patients with heart failure as having heart failure with reduced or preserved ejection fraction. Third, we showed a higher risk of IS/SE for patients with a higher HbA1c level, but whether aggressive glycemic control to achieve an $\mathrm{HbA} 1 \mathrm{c}$ level of $<6.5 \%$ can reduce the risk of AF-associated stroke deserves further study. Fourth, since DM is a risk factor of atherosclerosis, a considerable proportion of ischemic strokes occurring among AF patients with diabetes could be due to lacunar and atherothrombotic cerebral infarction rather than cardiogenic thromboembolism. However, information about the etiologies of ischemic stroke was not available in our database. Fifth, a high percentage (73\%) of AF patients did not receive long-term $\mathrm{OACs}$ for stroke prevention in our AF cohort. The mean $\mathrm{CHA}_{2} \mathrm{DS}_{2}$-VASc score of these patients was 3.2 (standard deviation 1.9 ) and $\sim 80 \%$ of them had a $\mathrm{CHA}_{2} \mathrm{DS}_{2}$-VASc score $\geq 2$. Actually, the underuse of OACs is a global issue, especially for Asian AF patients $[40,41]$. Multiple factors, such as the fear of bleeding and the inconvenience of warfarin, are related to the underuse of OACs. However, the exact causes of why those patients at risk of stroke did not receive OACs in our study were unclear. Lastly, data on TTR of INR for AF patients treated with warfarin were not available in our analysis. In general, Asians taking warfarin have difficulty in maintaining INR in the target range of $2-3$, and their TTR is substantially lower than that of patients in other parts of the world [41]. In addition, persistence of OAC treatment was assumed after the first prescription of an OAC. Moreover, prescriptions of other medications were confined to those taken at least once within 3 months before the index date, and the compliance was not verified. Therefore, residual confounding factors including the quality and persistence of OACs and other medications across the exposure groups could not be confirmed.

\section{Conclusions}

For AF patients, the risk of IS/SE significantly increased once the HbA1c levels exceeded $6.5 \%$, while the risk of major bleeding was comparable across all HbA1c levels. The use of OACs may attenuate the associations between HbA1c levels and the risk of IS/SE. Compared with warfarin, DOACs were more effective and safer across broad HbA1c categories. In addition to prescriptions of DOACs when indicated, more aggressive glycemic control to achieve an HbA1c level of $<6.5 \%$ may be considered for eligible AF patients, which should be tested in further prospective studies.

\section{Abbreviations}

ACEl: angiotensin-converting enzyme inhibitor; AF: Atrial fibrillation; ALT: Alanine aminotransferase; APT: Antiplatelet agent; ARB: Angiotensin II receptor antagonist; $\mathrm{CHA}_{2} \mathrm{DS}_{2}$-VASc: Congestive heart failure, hypertension, age 75 years or older, diabetes mellitus, previous stroke/transient ischemic attack, vascular disease, age 65 to 74 years, female; DOAC: Direct oral anticoagulant; eGFR: Estimated glomerular filtration rate; HAS-BLED: Hypertension, abnormal renal or liver function, stroke, bleeding history, labile INR, age 65 years or older, and antiplatelet drug or alcohol use; HbA1c: Glycated hemoglobin A1c; OHA: Oral hypoglycemic agent; NSAID: Nonsteroidal anti-inflammatory drug; TIA: Transient ischemic attack; DM: Type 2 diabetes mellitus.

\section{Acknowledgements}

The authors are grateful for the statistical assistance and support from the Maintenance Project of the Center for Big Data Analytics and Statistics (Grant CLRPG3D0045) at Chang Gung Memorial Hospital, regarding help with the study design and monitoring, data analysis, and interpretation. The authors are grateful for the assistance of English Grammar editing from the http://www. enago.tw and Boehringer Ingelheim, Taiwan.

\section{Authors' contributions}

YCC and CC contributed equally to the study and manuscript. YCC, CC, and TFC contributed to the conception and design of the study, analysis and interpretation of the data, wrote the manuscript, and approved submission. CCC and HFL contributed to the data acquisition and analysis. SHC and CLW collected the data. YCH and YTH contributed to analysis of data and provided critical revision of the paper. TFC, YHY, SAC, and CTK contributed to conception/design, and provided critical revision of the paper for the important intellectual content. All authors read and approved the final manuscript.

\section{Funding}

This study was supported by Grants 108-2314-B-182-053-MY2 and 105-2628-B-182A-003-MY3 from the Ministry of Science and Technology and Grants CMRPG3J1371, CMRPD 1 K0031, CMRPG3K0021, and CORPG3G0351 from Chang Gung Memorial Hospital, Linkou, Taiwan.

\section{Availability of data and materials}

The datasets used and/or analyzed during the current study are available from the corresponding author on reasonable request.

\section{Ethics approval and consent to participate}

The study protocol complies with the Declaration of Helsinki and was approved by the Institutional Review Board of the Chang Gung Medical Foundation.

\section{Consent for publication}

Not applicable. 


\section{Competing interests}

The authors declare that they have no competing interests.

\section{Author details}

${ }^{1}$ The Cardiovascular Department, Chang Gung Memorial Hospital, Linkou 33305, Taoyuan, Taiwan. ${ }^{2}$ College of Medicine, Chang Gung University, Taoyuan 33302, Taiwan. ${ }^{3}$ Microscopy Core Laboratory, Chang Gung Memorial Hospital, Linkou 33305, Taoyuan, Taiwan. ${ }^{4}$ Graduate Institute of Clinical Medical Sciences, College of Medicine, Chang Gung University, Taoyuan, Taiwan. ${ }^{5}$ Center for Big Data Analytics and Statistics, Chang Gung Memorial Hospital, Taoyuan, Taiwan. ${ }^{6}$ Division of Cardiology, Department of Medicine, Taipei Veterans General Hospital, No. 201, Sec. 2, Shih-Pai Road, Taipei, Taiwan. ${ }^{7}$ Institute of Clinical Medicine and Cardiovascular Research Center, National Yang-Ming University, Taipei, Taiwan

Received: 25 December 2019 Accepted: 24 February 2020 Published online: 10 March 2020

\section{References}

1. Chan YH, Chang GJ, Lai YJ, Chen WJ, Chang SH, Hung LM, Kuo CT, Yeh YH. Atrial fibrillation and its arrhythmogenesis associated with insulin resistance. Cardiovasc Diabetol. 2019;18(1):125.

2. Kim YG, Han KD, Choi Jl, Boo KY, Kim DY, Oh SK, Lee KN, Shim J, Kim JS, Kim YH. The impact of body weight and diabetes on new-onset atrial fibrillation: a nationwide population based study. Cardiovasc Diabetol. 2019:18(1):128.

3. Lip GY, Nieuwlaat R, Pisters R, Lane DA, Crijns HJ. Refining clinical risk stratification for predicting stroke and thromboembolism in atrial fibrillation using a novel risk factor-based approach: the euro heart survey on atrial fibrillation. Chest. 2010;137(2):263-72.

4. Gage BF, Waterman AD, Shannon W, Boechler M, Rich MW, Radford MJ. Validation of clinical classification schemes for predicting stroke: results from the National Registry of Atrial Fibrillation. JAMA 2001;285(22):2864-70.

5. Koenig RJ, Peterson CM, Jones RL, Saudek C, Lehrman M, Cerami A. Correlation of glucose regulation and hemoglobin Alc in diabetes mellitus. $\mathrm{N}$ Engl J Med. 1976;295(8):417-20.

6. American Diabetes Association. Executive summary: standards of medical care in diabetes-2009. Diabetes Care. 2009;32(Suppl 1):S6-12.

7. Kuusisto J, Mykkanen L, Pyorala K, Laakso M. Non-insulin-dependent diabetes and its metabolic control are important predictors of stroke in elderly subjects. Stroke. 1994;25(6):1157-64.

8. Selvin E, Coresh J, Shahar E, Zhang L, Steffes M, Sharrett AR. Glycaemia (haemoglobin A1c) and incident ischaemic stroke: the Atherosclerosis Risk in Communities (ARIC) Study. Lancet Neurol. 2005;4(12):821-6.

9. Sunaga K, Miura K, Naruse Y, Sakurai M, Morikawa Y, Kurosawa Y, Nakagawa H. Glycated hemoglobin and risk of stroke, ischemic and hemorrhagic. Japanese men and women. Cerebrovasc Dis. 2008;26(3):310-6.

10. Saliba W, Barnett-Griness O, Elias M, Rennert G. Glycated hemoglobin and risk of first episode stroke in diabetic patients with atrial fibrillation: a cohort study. Heart Rhythm. 2015;12(5):886-92.

11. Ashburner JM, Go AS, Chang Y, Fang MC, Fredman L, Applebaum KM, Singer DE. Effect of Diabetes and glycemic control on ischemic stroke risk in AF patients: ATRIA study. J Am Coll Cardiol. 2016;67(3):239-47.

12. Fangel MV, Nielsen PB, Kristensen JK, Larsen TB, Overvad TF, Lip GYH, Jensen MB. Glycemic status and thromboembolic risk in patients with atrial fibrillation and type 2 diabetes mellitus. Circ Arrhyth Electrophysiol. 2019;12(5):e007030.

13. Pisters R, Lane DA, Nieuwlaat R, de Vos CB, Crijns HJ, Lip GY. A novel user-friendly score (HAS-BLED) to assess 1-year risk of major bleeding in patients with atrial fibrillation: the Euro Heart Survey. Chest. 2010;138(5):1093-100.

14. Hylek EM, Held C, Alexander JH, Lopes RD, De Caterina R, Wojdyla DM, Huber K, Jansky P, Steg PG, Hanna M, et al. Major bleeding in patients with atrial fibrillation receiving apixaban or warfarin: the ARISTOTLE Trial (Apixaban for reduction in stroke and other thromboembolic events in atrial fibrillation): predictors, characteristics, and clinical outcomes. J Am Coll Cardiol. 2014;63(20):2141-7.
15. Brambatti M, Darius H, Oldgren J, Clemens A, Noack HH, Brueckmann M, Yusuf S, Wallentin L, Ezekowitz MD, Connolly SJ, et al. Comparison of dabigatran versus warfarin in diabetic patients with atrial fibrillation: results from the RE-LY trial. Int J Cardiol. 2015;196:127-31.

16. Wang CL, Wu VC, Kuo CF, Chu PH, Tseng HJ, Wen MS, Chang SH. Efficacy and safety of non-vitamin $\mathrm{k}$ antagonist oral anticoagulants in atrial fibrillation patients with impaired liver function: a retrospective cohort study. J Am Heart Assoc. 2018;7(15):e009263.

17. Shao SC, Chan YY, Kao Yang YH, Lin SJ, Hung MJ, Chien RN, Lai CC, Lai EC. The Chang Gung Research Database-a multi-institutional electronic medical records database for real-world epidemiological studies in Taiwan. Pharmacoepidemiol Drug Saf. 2019;28(5):593-600.

18. Wang CL, Wu VC, Lee CH, Kuo CF, Chen YL, Chu PH, Chen SW, Wen MS See LC, Chang SH. Effectiveness and safety of non-vitamin-K antagonist oral anticoagulants versus warfarin in atrial fibrillation patients with thrombocytopenia. J Thromb Thrombolysis. 2018:47(4):512-9.

19. American Diabetes A. Standards of medical care in diabetes-2010. Diabetes Care. 2010;33(Suppl 1):S11-61.

20. Lip GYH, Banerjee A, Boriani G, Chiang CE, Fargo R, Freedman B, Lane DA, Ruff CT, Turakhia M, Werring D, et al. Antithrombotic therapy for atrial fibrillation: CHEST guideline and expert panel report. Chest. 2018;154(5):1121-201.

21. Lip GYH, Freedman B, De Caterina R, Potpara TS. Stroke prevention in atrial fibrillation: past, present and future. Thromb Haemost. 2017:117(7):1230-9.

22. American Diabetes A. Executive summary: standards of medical care in diabetes-2014. Diabetes Care. 2014;37(Suppl 1):S5-13.

23. Patti G, Di Gioia G, Cavallari I, Nenna A. Safety and efficacy of nonvitamin $\mathrm{K}$ antagonist oral anticoagulants versus warfarin in diabetic patients with atrial fibrillation: a study-level meta-analysis of phase III randomized trials. Diabetes Metab Res Rev. 2017:33:3.

24. Ilomaki J, Helin-Salmivaara A, Huupponen R, Rikala M, Kirkpatrick $\mathrm{CM}$, Korhonen MJ. Analgesic use before and after oral anticoagulant initiation-a population-based study in Finland. Eur J Clin Pharmacol. 2015;71(6):723-32.

25. Davidson BL, Verheijen S, Lensing AW, Gebel M, Brighton TA, Lyons RM, Rehm J, Prins $\mathrm{MH}$. Bleeding risk of patients with acute venous thromboembolism taking nonsteroidal anti-inflammatory drugs or aspirin. JAMA Intern Med. 2014;174(6):947-53.

26. Chuang SY, Yu Y, Sheu WH, Tsai YT, Liu X, Hsiung CA, Tsai HJ. Association of short-term use of nonsteroidal anti-inflammatory drugs with stroke in patients with hypertension. Stroke. 2015:46(4):996-1003.

27. Kent AP, Brueckmann M, Fraessdorf M, Connolly SJ, Yusuf S, Eikelboom JW, Oldgren J, Reilly PA, Wallentin L, Ezekowitz MD. Concomitant oral anticoagulant and nonsteroidal anti-inflammatory drug therapy in patients with atrial fibrillation. J Am Coll Cardiol. 2018;72(3):255-67.

28. Action to Control Cardiovascular Risk in Diabetes Study G, Gerstein HC, Miller ME, Byington RP, Goff DC Jr, Bigger JT, Buse JB, Cushman WC, Genuth S, Ismail-Beigi F, et al. Effects of intensive glucose lowering in type 2 diabetes. N Engl J Med. 2008;358(24):2545-59.

29. Group AC, Patel A, MacMahon S, Chalmers J, Neal B, Billot L, Woodward M, Marre M, Cooper M, Glasziou P, et al. Intensive blood glucose control and vascular outcomes in patients with type 2 diabetes. N Engl J Med. 2008;358(24):2560-72.

30. Bansilal S, Bloomgarden Z, Halperin JL, Hellkamp AS, Lokhnygina Y, Patel MR, Becker RC, Breithardt G, Hacke W, Hankey GJ, et al. Efficacy and safety of rivaroxaban in patients with diabetes and nonvalvular atrial fibrillation: the Rivaroxaban Once-daily, Oral, Direct Factor Xa Inhibition Compared with Vitamin K Antagonism for Prevention of Stroke and Embolism Trial in Atrial Fibrillation (ROCKET AF Trial). Am Heart J. 2015;170(4):675-82.

31. Connolly SJ, Ezekowitz MD, Yusuf S, Eikelboom J, Oldgren J, Parekh A, Pogue J, Reilly PA, Themeles E, Varrone J, et al. Dabigatran versus warfarin in patients with atrial fibrillation. N Engl J Med. 2009;361(12):1139-51.

32. Granger CB, Alexander JH, McMurray JJ, Lopes RD, Hylek EM, Hanna M, Al-Khalidi HR, Ansell J, Atar D, Avezum A, et al. Apixaban versus warfarin in patients with atrial fibrillation. N Engl J Med. 2011;365(11):981-92.

33. Ezekowitz JA, Lewis BS, Lopes RD, Wojdyla DM, McMurray JJ, Hanna M, Atar D, Cecilia Bahit M, Keltai M, Lopez-Sendon JL, et al. Clinical outcomes of patients with diabetes and atrial fibrillation treated with apixaban: results from the ARISTOTLE trial. Eur Heart J CardiovasC Pharmacother. 2015;1(2):86-94. 
34. Itzhaki B, Zadok O, Eisen A. Use of non-vitamin K oral anticoagulants in people with atrial fibrillation and diabetes mellitus. Diabet Med. 2018;35(5):548-56.

35. Plitt A, McGuire DK, Giugliano RP. Atrial fibrillation, type 2 diabetes, and non-vitamin k antagonist oral anticoagulants: a review. JAMA Cardiol. 2017;2(4):442-8.

36. Baraka-Vidot J, Guerin-Dubourg A, Bourdon E, Rondeau P. Impaired drugbinding capacities of in vitro and in vivo glycated albumin. Biochimie. 2012:94(9):1960-7.

37. Nelson WW, Desai S, Damaraju CV, Lu L, Fields LE, Wildgoose P, Schein JR. International normalized ratio stability in warfarin-experienced patients with nonvalvular atrial fibrillation. Am J Cardiovasc Drugs. 2015;15(3):205-11.

38. Yamagishi SI. Concerns about clinical efficacy and safety of warfarin in diabetic patients with atrial fibrillation. Cardiovasc Diabetol. 2019;18(1):12.

39. Pridavkova D, Samos M, Bolek T, Skornova I, Zolkova J, Kubisz P, Stasko J, Mokan M. Type 2 diabetes, atrial fibrillation, and direct oral anticoagulation. J Diabetes Res. 2019;2019:5158308.
40. Chao TF, Liu CJ, Wang KL, Lin YJ, Chang SL, Lo LW, Hu YF, Tuan TC, Chen TJ, Lip GY, et al. Using the CHA2DS2-VASC score for refining stroke risk stratification in 'low-risk' Asian patients with atrial fibrillation. J Am Coll Cardiol. 2014;64(16):1658-65.

41. Oh S, Goto S, Accetta G, Angchaisuksiri P, Camm AJ, Cools F, Haas S, Kayani G, Koretsune Y, Lim TW, et al. Vitamin Kantagonist control in patients with atrial fibrillation in Asia compared with other regions of the world: real-world data from the GARFIELD-AF registry. Int J Cardiol. 2016;223:543-7.

\section{Publisher's Note}

Springer Nature remains neutral with regard to jurisdictional claims in published maps and institutional affiliations.
Ready to submit your research? Choose BMC and benefit from:

- fast, convenient online submission

- thorough peer review by experienced researchers in your field

- rapid publication on acceptance

- support for research data, including large and complex data types

- gold Open Access which fosters wider collaboration and increased citations

- maximum visibility for your research: over $100 \mathrm{M}$ website views per year

At BMC, research is always in progress.

Learn more biomedcentral.com/submissions 